\title{
РАЗВИТИЕ ТРАНСПОРТНО-ЛОГИСТИЧЕСКОГО СЕКТОРА В ГЕРМАНИИ
}

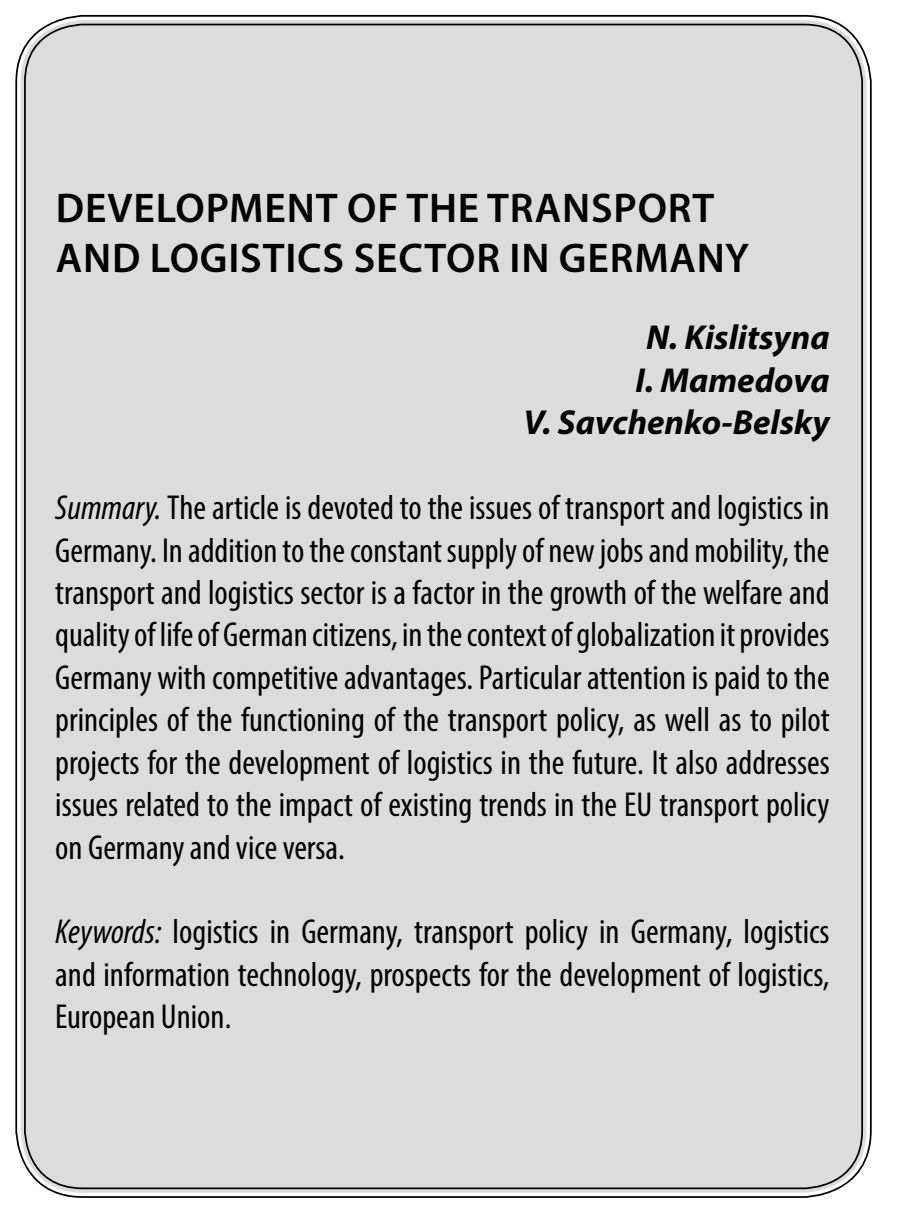

$\mathbf{T}$ ранспортно-логистический сектор (ТЛС) Германии является самым развитым в Европейском союзе. Согласно индексу эффективности логистики LPI 2018 Всемирного банка Германия среди 160 стран по всем критериям заняла первое место. Транспортная логистика выступает важным фактором роста благосостояния и качества жизни немецкого общества, а также создает возможность появления новых рабочих мест и обеспечения мобильности. Помимо этого, немецкая логистика обладает большими резервными возможностями саморазвития и обеспечивает Германии конкурентные преимущества на мировом уровне. В 2017 году товарооборот составил около 267 миллиардов евро. По показателям оборачиваемости логистического рынка (150 млрд. евро) ФРГ находится на четвертом месте, уступая автомобилестроению, электротехнической промышленности и общему машиностроению, а по числу задействованного персонала она занимает лидирующую позицию (2,6 млн. чел. в отрасли). В марте 2020 количество наемных работников достигло отметки в 45,13 миллионов человек [1], из них в сфере логистики занято
Кислицына Наталия Феликсовна

К.ю.н., дочент, Российский университет транспорта (РУТ(МИИТ))

kis-nataliya@yandex.ru Мамедова Ирада Ахатовна К.э.н., доцент, Российский университет транспорта (РУТ(МИИТ))

irada-mamedowa@mail.ru

Савченко-Бельский Владимир Юрьевич

Д.э.н., профессор, Институт отраслевого менеджмента, г. Москва; ФГБОУ ВО «Государственный университет управления» s-b_v@mail.ru

Аннотация. Статья посвящена вопросам транспортно-логистического сообщения в Германии. Помимо постоянного предложения новых рабочих мест и обеспечения мобильности, транспортно-логистический сектор является фактором роста благосостояния и качества жизни немецких граждан, в условиях глобализации обеспечивает Германии конкурентные преимущества. Особое внимание в статье уделяется принципам функционирования транспортной политики, а также на пилотных проектах по развитию логистики в будущем. Также рассматриваются вопросы, связанные с влиянием существующих тенденций в рамках транспортной политики ЕС на Германию и наоборот.

Ключевые слова: логистика в Германии, транспортная политика Германии, логистика и информационные технологии, перспективы развития логистики, Европейский союз.

около 5\%. Согласно закону о минимальной заработной плате предприятия в транспортной отрасли обязаны выплачивать персоналу минимальную зарплату (составляет около 10 евро в час), даже если сотрудники работают временно.

Главной задачей транспортной инфраструктуры и логистики Германии - развитие логистической отрасли. Германия находится в самом центре Европейского союза, что позволяет ей быть страной с очень выгодной геополитической позицией. В Германии находятся много крупных логистических компаний с мировым именем: Deutsche Post (DHL), Deutsche Bahn, Stinnes, Schenker, Kuhne \& Nagel, FIEGE и Rhenus.

Текущая транспортная политика Германии основывается на соблюдении трех базовых принципов:

- экономический: ТЛС должен служить фактором роста благосостояния граждан и конкурентоспособности страны, а также увеличивать занятость населения; 
- экологический: ТЛС не должен негативно влиять на экологию;

- социальный:ТЛС должен способствовать мобильности граждан, их безопасности передвижения и благоприятным условиям труда.

Также транспортная политика Германии имеет три вектора развития:

1. рост мобильности населения

2. создание и поддержание благоприятных условий для здоровой конкуренции между транспортными компаниями

3. развитие транспортной инфраструктуры страны и кооперация с мировыми транспортными системами

Германия считается основным игроком на европейском рынке транспортных услуг: 21\% всех перевозок в Европе приходится именно на нее. Оборот логистического рынка Европы за 2017 г. составил 1.050 млрд. евро, и на Германию приходится около 25\%.

Эффективность перевозок по всем видам транспорта в 2018 составила около 660 млрд. тонно-километров, из них 470 млрд. приходятся на долю автомобильных перевозок. Общий объем перевозок грузов по железной дороге в 2018 г. составил 360 млн. тонн. Грузовые и морские перевозки в 2018 г. увеличились на 1\% по сравнению с 2017 г. Количество экспедиторов в Германии в 2018 г. составило 14807 чел. Согласно рейтингу стран мира по эффективности железнодорожного сообщения в 2018 г. на первом месте оказалась Швейцария с 6,7 баллами из 7 возможных, а за ней следует Германия. В Германии оперируют признанные мировые лидеры логистики (Deutsche Post (DHL), DB Schenker, Deutsche Bahn, Schenker, Kuhne \& Nagel, FIEGE и Rhenus), на которых приходится одна треть европейского рынка логистических услуг.

Согласно еще одному закону в транспортной отрасли Германии движение по дорогам страны с 2020 г. стало частично платным. Стоимость проезда будет зависеть от модели автомобиля, от выделения вредных выбросов в окружающую среду и будет составлять от 3 до 130 евро. Наименьшая оплата предусмотрена для владельцев самых новых моделей автомобилей, электромобилей и автомобилей, управляемых людьми с ограниченными возможностями здоровья. Транзитные автомобили будут платить только за использование дорог, а автобусы и грузовики освобождаются от сборов.

Остальным видам транспорта уступает водный, так как судоходные компании находятся на грани банкротства из-за большого объема кредитов, выданных банками земель северной Германии контейнерным перевозчикам. Земли Гамбург и Шлезвиг-Гольштейн ожидают от правительства до 20 млрд. евро гарантий банкам, иначе имеющийся избыток мощностей на международном рынке контейнерных перевозок не позволит немецким контейнеровозам работать в полную мощность и осуществлять поставки, покрывающие затраты.

При неблагоприятном развитии ситуации в будущем могут потребоваться субсидии от ЕС для поддержания финансовой стабильности таких банков как HSH Nordbank, Nord Landesbank и DVB Bank.

Авиационная отрасль Германии имеет также немаловажное экономическое значение. На 1 января 2018 г. воздушный фрахт составлял 6,985 млн. тонн/км, а также перевезено 115 млн. пассажиров. Помимо прочего, согласно данным на 2018 г. более 800 <000 человек было занято в авиационной отрасли.

Германия является главным торговым партнером России в области поставок технологически сложного промышленного и медицинского оборудования, запчастей и комплектующих, высокоточных приборов и т.д.

Традиционно большое внимание уделяется технологиям IT, которые направлены на мобильность и прозрачность перемещения всех данных, а также на кооперацию различных цифровых систем друг с другом, то есть на развитие новых кибер-систем и логистических агрегаторов.

Логистика становится источником новых типов дистрибуции и бизнес-моделей. Такие новые игроки, как новые электронные платформы, мешают традиционным посредникам в логистике.

Три четверти жителей Германии уже проживают в городах, а к 2050 г. согласно статистическим данным ООН, эта цифра составит 84\%. Столь плотное количество населения в небольших пространствах должно будет обеспечиваться всеми видами продуктов, лекарствами и т.д. Благодаря онлайн-трейдингу и многоканальным цепям поставок объемы поставок будут постоянно увеличиваться.

Также набирают популярность малошумные ночные поставки, для которых в будущем будут использоваться электромобили. В настоящее время уже проводятся разработки подземной транспортной системы с сетью тоннелей, где с помощью технологии магнитной левитации капсулы без водителя с двумя паллетами каждая будут скользить по большим трубам. Эта система будет работать на возобновляемых источниках энергии.

В конце 2018 г. в рамках экспериментального проекта по специальному участку автострады А9 начались 
испытания двух подключенных к сети грузовиков с автоматизированным управлением. Грузовики отправилась из филиала компании DB Schenker в Нойфарне под Мюнхеном в Нюрнберг. Проект был осуществлён при участии крупнейшего в мире поставщика логистических услуг DB Schenker совместно с компанией MAN Truck \& Bus и Университетом прикладных наук им. Фрезениуса. Правительство Германии выделило около 2 млн. евро на финансирование проекта. Этот проект пилотируемой колонны повышает необходимость разработок в сфере автоматизированного управления через подключение к сети. Впервые в истории логистики уделяется внимание влияния ноу-хау технологий на нейрофизиологическое и психосоциальное поведение водителя, что предъявляет новые требования к сотрудникам логистической индустрии.

Одним из направлений развития складской логистики будет построение складов для всех поставщиков, где товары консолидируются, а затем доставляются на одном транспортном средстве с низким уровнем выбросов в окружающую среду. Это позволит сократить трафик доставки в государственные учреждения на 40\%.

Городская логистика в ближайшем десятилетии будет эффективно функционировать, если последняя миля будет пройдена всеми участниками поставки вместе. Даже офисные здания могут послужить складом вне часов работы, что освободит улицы в течение дня.

Совершенно новые возможности для логистического бизнеса будут заключаться в подключении каждого грузовика к облаку, что позволит отслеживать данные в реальном времени, а также позволит избежать порожних пробегов.

Из выше сказанного, на наш взгляд, формулируется один вывод: Германия продолжает заниматься лидирующие позиции по многим показателям, в том числе в отношении перевозок различными видами транспорта, среди всех государств-членов Европейского Союза. В связи с этим возникает немаловажный вопрос: как согласуется деятельность Германии с общей транспортной политикой Европейского Союза. Для ответа, прежде всего, потребуется понимание того, что же на сегодняшний день представляет собой транспортная политика Европейского Союза (далее ЕС).

Если в целом говорить о деятельности ЕС, то к его истории, а также ко всем современным направлениям деятельности проявляют интерес многие ученые. Вопросы, связанные с изучением деятельности ЕС в различных сферах, в том числе и транспорта, также особенности сотрудничества ЕС с государствами, не входящими в состав данного интеграционного объединения, так или иначе изложены в работах как отечественных юристов-международников, так и зарубежных. Среди отечественных специалистов следует выделить работы: А.Я. Капустина [2]; И.И. Лукашука [3]; Ю. М. Колосова [4]. Среди зарубежных специалистов в области международного публичного права и права ЕС следует выделить: Кристофер Ходж [5]; Винсент Ламанд [6]; Мустафа Тюркес [7].

Итак, самое простое определение «транспортной политики ЕС», на наш взгляд, является: непосредственная международно-правовая деятельность всех институтов EC, а также самих государств-членов в сфере транспорта. Это деятельность подразумевает разработку и принятие норм и принципов международного права, которые будут регламентировать взаимоотношения государств по поводу использования всех видов транспорта с целью осуществления перевозки пассажиров и их багажа, а также грузов, как обычных, так и опасных. Если проанализировать все имеющиеся международно-правовые документы, разработанные в рамках ЕС, наиболее близкими к сфере транспорта можно отнести следующие: прежде всего, это «Дорожная карта ЕС к единой европейской транспортной зоне: в направлении к конкурентоспособной и ресурсоэффективной транспортной системе» [8] 2011 г., неофициальное название - Белая книга EC (COM/2011/0144final). Также не стоит забывать про раздел 6 «Транспорт» договора о реформе - Лиссабонский договор 2007 г., вступившего в силу в 2009 г. [9].

Итак, указанный раздел Договора о реформе 2007 г. запрещает осуществлять дискриминацию, которая выражается в виде применения перевозчиком, одним из ключевых участников процесса, тарифов и условий перевозки, различающихся в зависимости от страны происхождения или назначения перевозимой продукции.

Основным моментом в выстраивании транспортных отношений между первичными субъектами международного публичного права, имеются в виду государства, является установление Лиссабонским договором запрета возлагать государствам-членам обязанности устанавливать тарифы, включающие в себя любые элементы поддержки или защиты в интересах одного или нескольких конкретных предприятий. Также следует отметить: «сборы и платежи, которые независимо от транспортных тарифов взимаются перевозчиком за пересечение границ, не должны превышать разумного уровня с учетом реальных издержек, действительно вызванных таким пересечением» [10]. В данном международно-правовом документе указано еще одно важное правило, в соответствии с которым государства-члены должны прилагать все возможные усилия по постепенному сокращению данных издержек. С другой стороны, Европейская комиссия имеет возмож- 
ность направлять государствам-членам рекомендации по данному вопросу. На наш взгляд, наиболее интересным фактом рассматриваемого международно-правового документа, можно считать создание комитета консультативного характера в составе экспертов, назначаемых правительствами государств-членов. Европейская комиссия консультируется с данным комитетом по вопросам транспорта всякий раз, когда считает это необходимым.

Что касается Белой книги, то в ней представлены конкретные действия, которые необходимо реализовать в течение следующих 20-30 лет, с целью создания конкурентоспособной транспортной системы, которая позволит устранить основные пробелы, эффективно и безопасно перемещать людей и товары по всей территории ЕС. Эти предложения должны снизить зависимость ЕС от импортируемой нефти, к 2030 году обеспечить мобильность городов без выбросов углекислого газа в крупных городских центрах и сократить к 2050 году выбросы углекислого газа на $60 \%$.

Согласно положениям Дорожной карты ЕС, на наш взгляд, следует акцентировать внимание на разделе под названием «Стратегия - что необходимо предпри- нять». В нем четко обозначены последующие шаги государств-членов ЕС:

1. задача на следующее десятилетие - создать подлинную единую европейскую транспортную зону, устраняя все остаточные барьеры между видами транспорта и национальными системами, облегчая процесс интеграции и способствуя появлению многонациональных и мультимодальных операторов;

2. исследования ЕС должны охватывать полный цикл исследований, инноваций и внедрения комплексным образом, фокусируясь на наиболее перспективных технологиях и объединяя всех участников;

3. усилия по созданию более конкурентоспособной и устойчивой транспортной системы должны включать анализ требуемых характеристик транспортной сети и предусматривать адекватные инвестиции: политика ЕС в вопросах транспортной инфраструктуры требует общего видения и достаточных ресурсов.

Постепенная реализация задач, поставленных в рамках Белой книги ЕС, подтверждается проанализированными статистическими данными Германии.

\section{ЛИТЕРАТУРА}

1. Федеральное управление статистики Германии [Электронный ресурс] / Statistisches Bundesamt April 2020 URL: https:/de.statista.com/statistik/daten/ studie/1376/umfrage/anzahl-der-erwerbstaetigen-mit-wohnort-in-deutschland/\#professional (дата обращения 31.05.2020).

2. Капустин А. Я. Общая характеристика основных принципов конституционной системы Европейского Союза // Правоведение. С.-Пб.: Изд-во С.- Петербург. ун-та, 2000. № 1. С. 217-236.

3. Лукашук И. И. Роль принципов в механизме международно-правового регулирования социалистической экономической интеграции // Принципы социалистической экономической интеграции. М.: Изд-во ИГиП АН СССР, 1985, Ч. 1. С. $28-53$.

4. Колосов Ю. М. Роль международного права в нашей жизни (к выходу в свет брошюры Г. И. Морозова «Международное право и международные отношения (проблемы взаимосвязи)») // Московский журнал международного права. М.: Междунар. Отношения. 1997. № 2. С. $164-166$.

5. Christopher Hodges European Union Legislation The ANNALS of the American Academy of Political and Social Science, vol. 622, $2009,1:$ pp. 78-85.

6. Vincent Lamande, Ivan Samson, Evgeny Vinokurov Measuring Regional Economic Development in Russia: The Case of the Kaliningrad Oblast European Urban and Regional Studies, vol. 11, 2004, 1: pp. 71-80.

7. Mustafa Türkes, Göksu Gökgöz The European Union's Strategy towards the Western Balkans: Exclusion or Integration? East European Politics and Societies, vol. 20, 2006, 4: pp. 659-690.

8. Белая книга EC (COM/2011/0144 final) [Электронный ресурс] «Дорожная карта ЕС к единой европейской транспортной зоне: в направлении к конкурентоспособной и ресурс эффективной транспортной системе». // URL: http://eur-lex.europa.eu/legal-content/EN/TXT/PDF/?uri=CELEX:52011DC0144\&from=EN (дата обращения 20.05.2020).

9. Лиссабонский договор 2009 г. [Электронный ресурс] // URL: https://publications.europa.eu/en/publication-detail/-/publication/3c32722f-0136-4d8f-a03ebfaf70d16349(дата обращения 20.05.2020).

10. Статья 97 Лиссабонского договора 2009 г. [Электронный ресурс]// URL: https://europa.eu/european-union/sites/europaeu/files/eu_citizenship/consolidatedtreaties_en.pdf\#page=86 (дата обращения 20.05.2020).

(с) Кислицына Наталия Феликсовна ( kis-nataliya@yandex.ru ), 